\title{
Different Effects of Olive Leaf on Purine Metabolizing Enzymes of Human Gastric Tissues in Vitro
}

\author{
Hikmet Can Çubukçu*1, Zahide Esra Durak ${ }^{2}$, Ender Hilmi Kocaoğlu ${ }^{3}$ and İlker Durak ${ }^{1}$ \\ ${ }^{1}$ Department of Medical Biochemistry, Ankara University Faculty of Medicine Turkey \\ ${ }^{2}$ Institution of Public Health, Turkish Ministry of Health, Turkey \\ ${ }^{3}$ Surgical Oncology Department, Faculty of Medicine, Ankara University, Turkey
}

Submission: August 10, 2018; Published: September 14, 2018

"Correspondence Address: Hikmet Can Çubukçu, Ankara University Faculty of Medicine, Department of Medical Biochemistry, Morphology building, 06100 Sihhiye/Ankara -Turkey, Turkey, Tel: +903125958268; Email: hikmetcancubukcu@gmail.com

\section{Abstract}

Olive leaf (Olea europaea leaf) is a natural food source known to have anticarcinogenic, antiproliferative and anti-inflammatory effects in different types of tissues. Adenosine deaminase, 5'nucleotidase and xanthine oxidase are enzymes playing part in purine metabolism including salvage pathway. In the present study, it is aimed to investigate possible inhibitory effects of aqueous extract of olive leaf on different purine metabolizing enzyme activities in benign and malign human gastric tissues. Fouteen cancerous and 14 adjacent noncancerous human gastric tissues were surgically removed from patients underwent surgical operation. Olive leaf extract- treated and - not treated tissues were analyzed in vitro for adenosine deaminase , 5'-nucleotidase and xanthine oxidase activities.

Our results showed that aqueous extract of olive leaf inhibited adenosine deaminase activity significantly in cancerous gastric tissue $(\mathrm{p}=0.000)$ and $5^{\prime}$-nucleotidase activity in non cancerous gastric tissue $(\mathrm{p}=0.001)$. However, no significant differences were found between tissue xanthine oxidase activities. Results indicate that aqueous extract of olive leaf may exhibit anti-cancer activites by inhibiting adenosine deaminase and 5'nucleotidase in gastric tissues.

Keywords: Olive leaf; Cancer; Adenosine deaminase; 5'-nucleotidase, Xanthine oxidase; Oleuropein; Apigenin; Luteolin; Quercetin; Tyrosol; Hydroxytyrosol; Caffeic acid; Ferulic acid; p-Coumaric acid; Cancer

\section{Introduction}

Cancer is increasingly becoming a worldwide public health problem. 14.1 million new cancer cases and 8.2 million cancer deaths were reported in 2012 worldwide. It is expected that by 2025, 20 million new cancer cases are diagnosed each year. The most common cancer types are lung , breast, and colorectal cancer respectively [1]. Gastric cancer is the fourth most common cancer and second most common cause of cancer deaths worldwide [2]. While radiotherapy and chemotherapy are used to treat these cancers, severe side effects can be seen in some patients. Recently natural and herbal remedies have taken attention owing to their represented ability to treat some diseases like cancer. Natural products can be used not only to treat cancer but also to prevent it [3]. Smoking cessation, fruit and vegetable intake, reducing salt intake, Helicobacter pylori eradication can help prevent from gastric cancer [4].

Olea europaea is an evergreen tree which belongs to Oleaceae family. The plant is cultivated widely in Mediterranean basin [5]. While the fruits and the oil are consumed for nutrition, olea europaea leaf has been used as a folk remedy for centuries.
Studies have shown that olive leaf has antiproliferative, apoptotic, antiatherosclerotic, antioxidant, antidiabetic, antiHIV and antifungal properties. Olive leaf contains several phenolic compounds like oleuropein, apigenin, luteolin, quercetin, tyrosol, hydroxytyrosol, caffeic acid, ferulic acid. The potential health benefits of olive leaf have mainly attributed to these bioactive substances [6]. Adenosine deaminase (ADA) is an enzyme involved in purine metabolism which deaminates adenosine and deoxyadenosine to inosine and deoxyinosine respectively. It plays an important role in differentiation of the lymphoid system. ADA deficiency related to severe combined immunodeficiency disease (SCID) .Therefore ADA inhibitors are used to treat lymphoproliferative disorders as an immunosuppressive therapy [7].

5'nucleotidases are important enzymes for maintaining nucleotide pools which dephosphorylate nucleoside monophosphates to nucleosides and inorganic phosphates. Nucleoside triphosphates necessary for maintaining vital cellular processes. Since 5'-nucleotidases are responsible 


\section{Cancer Therapy \& Oncology International Journal}

for degradation of nucleoside monophosphates, they can regulate cellular energy homeostasis by changing nucleoside triphosphate to monophosphate ratio [8].

Xanthine oxidase $(\mathrm{XO})$ is involved in purine metabolism catalyzing the oxidation of hypoxanthine to xanthine, and xanthine to uric acid [9]. It generates superoxide radicals and hydrogen peroxide during oxidation [10]. These reactive oxygen substances may contribute to various diseases like cancer [9]. It has also been reported that XO may be a crucial therapeutic target for some diseases like gout, cancer, inflammation and oxidative damage [11]. The present study aims to clarify possible proposed anticarcinogenic effects of aqueous olive leaf extract with regard to purine metabolizing enzyme activities of human gastric tissues in vitro.

\section{Methods}

Fourteen cancerous and 14 adjacent noncancerous human gastric tissues were obtained from patients by surgical operation. After cleaned by saline solution, fresh surgical specimens were stored at $-80{ }^{\circ} \mathrm{C}$ until analysis. Before analysis procedure, specimens were first homogenized by DIAX 900 (Heidolph, Kelhaim, Germany) in saline solution (20\%, w/v). The homogenates were centrifuged at $5000 \mathrm{rpm}$ for $30 \mathrm{~min}$ by a Harrier 18/80 centrifuge (MSE, London, UK) to remove debris. Then, clear supernatant fractions were taken for enzymatic analysis. Aqueous extract of olive leaf (Olea europaea leaf) was prepared at concentration of $10 \%(\mathrm{w} / \mathrm{v})$ in distilled water. Tissue homogenates were treated with aqueous extract of olive leaf for 1 hour.

Enzyme activities were measured in the specimens with and without olive leaf extract spectrophotometrically by using Helios alpha Ultraviolet/Visible Spectrophotometer (Unicam, Cambridge, UK). Protein concentration in the samples was measured by the method of Lowry, and adjusted to equal concentrations [12]. ADA activities were measured by Giusti method. The method is based on spectrophotometric measurement of a blue colored dye occurred after the reaction of ammonia (product of adenosine deamination) with phenol nitroprusside and alkaline hypochlorite solution [13]. Xanthine oxidase activities were evaluated by measuring uric acid formation from xanthine at $293 \mathrm{~nm}$ [14], and 5'-nucleotidase activities were performed by determination of liberated phosphate at $680 \mathrm{~nm}$ as described previously [15] .

Statistical evaluations between groups were made by using Mann-Whitney U test, and p values lower than 0.05 were evaluated significant. All statistical calculations were performed by using SPSS statistical software (SPSS for Windows, version 11.5)

\section{Results}

ADA, 5'-NT and XO activities are shown in the Table 1, and p values in the Table 2 . It has been observed that aqueous extract of olive leaf inhibited adenosine deaminase in malign gastric tissue $(\mathrm{p}=0.000)$, and 5 '-nucleotidase in benign gastric tissue $(p=0.001)$ significantly. However, no significant differences were found between tissue xanthine oxidase activities. Although ADA activities in the treated benign tissues, and 5'-nucleotidase activities in the treated malign tissues were lower than those in the non- treated tissues, they were not significant statistically ( $p=0.067, p=0.062)$. In addition, we found no meaningful differences between benign and malign tissue enzyme activities.

Table 1: Effects of aqueous olive leaf extract on ADA, 5'nucleotidase, xanthine oxidase activities in cancerous and non-cancerous human gastric tissues. Enzyme activities were expressed in $\mathrm{mlU} / \mathrm{mg}$ and given as mean \pm standart deviation.

\begin{tabular}{|c|c|c|c|c|}
\hline & \multicolumn{2}{|c|}{ Benign Tissue } & \multicolumn{2}{c|}{ Malign Tissue } \\
\hline $\begin{array}{c}\text { Enzyme } \\
\text { Activities }\end{array}$ & $\begin{array}{c}\text { Without } \\
\text { Extract }\end{array}$ & $\begin{array}{c}\text { With } \\
\text { Extract }\end{array}$ & $\begin{array}{c}\text { Without } \\
\text { Extract }\end{array}$ & $\begin{array}{c}\text { With } \\
\text { Extract }\end{array}$ \\
\hline $\begin{array}{c}\text { Adenosine } \\
\text { Deaminase }\end{array}$ & $\begin{array}{c}\text { (A) } 38.58 \pm \\
31.17\end{array}$ & $\begin{array}{c}\text { (B) } 17.71 \pm \\
12.97\end{array}$ & (C) $46.31 \pm$ & (D) $17.71 \pm$ \\
\hline 5'nucleotidase & (E) $16.95 \pm$ & (F) $1.63 \pm$ & (G) $27.71 \pm$ & 14.08 \\
\hline $\begin{array}{c}\text { Xanthine } \\
\text { oxidase }\end{array}$ & 14.32 & 2.1 & 26.78 & 5.27 \\
\hline
\end{tabular}

Table 2: Statistical evaluation of groups by Mann-Whitney $U$ test.

\begin{tabular}{|c|c|}
\hline Groups & p values \\
\hline A-C & 0.590 \\
\hline A-B & 0.067 \\
\hline C-D & $0.000^{*}$ \\
\hline E-G & 0.519 \\
\hline E-F & $0.001^{*}$ \\
\hline G-H & 0.062 \\
\hline I-K & 0.631 \\
\hline I-J & 0.482 \\
\hline K-L & 0.538 \\
\hline
\end{tabular}

\section{Discussion}

Natural remedies have been used from ancient times till now in conventional Eastern medicine. It has been known that more plant consumption reduces the incidence rates of cancer. Phenolic compounds are those of the plant ingredients that represent anticancer properties [16]. Olive leaf contains various phenolic compounds including oleuropein, ligstroside aglycone, oleuropein aglycone, quercetin, isorhamnetin, rutin, catechin, gallocatechin, apigenin, luteolin, tyrosol, hydroxytyrosol, gallic acid, p-coumaric acid, caffeic acid and ferulic acid that contribute to anti-carcinogenic, antioxidant, anti-inflammatory and antimicrobial effects [17].

Researchers have demonstrated that hydroxytyrosol-rich extract of the olive leaf can inhibit human breast cancer cell growth owing to cell cycle arrest in the G0/G1 phase [18]. Oleuropein and its semisynthetic peracetylated derivatives have been documented for its antiproliferative and antioxidant effects on human breast cancer cell lines [19]. Olive leaf extract's 


\section{Cancer Therapy \& Oncology International Journal}

antigenotoxic, antiproliferative and proapoptotic activities on human promyelocytic leukemia cells were previously reported [20]. Further researchers have shown that dry olive leaf extract possesses strong anti melanoma potential by reducing tumour volume, inhibiting proliferation,causing cell cycle arrest [21]. Studies have also demonstrated gastroprotective activity of olive leaf [22] and antioxidant effects on ethanol-induced intestinal mucosal damage [23].

ADA is responsible for adenosine and inosine breakdown Inhibition of ADA blocks the deamination of purine nucleotides, and as a consequence accumulation of ADA substrate, 2-deoxyadenosine inhibits ribonucleotide reductase. This process leads to a reduction of nucleotide pool, and limits DNA syntesis [24]. Phosphorylation of deoxyadenosine results in deoxyadenosine triphosphate production. Deoxyadenosine triphosphate and deoxyadenosine both inactivate S-adenosinehomocysteinase [25] and affect cellular methylation of some substances like proteins, DNA and RNA [26]. There are many studies as to the ADA activation on different pathologic conditions. Inhibition of ADA was found to reduce intestinal inflammation in experimental colitis [27]. A study on human gastric cancer cell line has also shown that extracellular adenosine induces apoptosis [28]. It is known that chronic inflammation predisposes to gastric cancer [29]. Adenosine reflects its metabolic function by its four G-protein coupled receptors. Adenosine A2A reseptor activation possesses antiinflammatory effects on various conditions [30].

In the present study, aqueous extract of olive leaf was found to inhibite adenosine deaminase in malign gastric tissue $(p=0.000)$, significantly. Inhibition of ADA can promote adenosine accumulation, and therefore it not only induces apoptosis but also exhibit anti-inflammatory effects on gastric cancerous tissue. 5'nucleotidases are responsible for degradation of nucleoside monophosphates. Until now, 7 types of human 5 '-nucleotidases have been identified [8]. One of them is ecto- $5^{\prime}$-nucleotidase that is also known as CD73. Studies have implied that ecto-5'nucleotidase regulates proliferation, migration and invasion of cancer cells in vitro, tumor angiogenesis and tumor immune evasion in vivo [31]. Nucleoside analogues are used as both anticancer and antiviral agents. These drugs inhibit DNA syntesis by its active substances. Studies have shown that enhancing nucleotidase activity can cause anticancer drug resistence by inhibiting nucleoside analogue activation [8]. Moreover, Lu et al have reported that CD73 expression in malign gastric tissues is higher than benign gastric tissues. This study has also indicated that CD 73 overexpression is related to differentiation of tumour depth of invasion, stage and metastasis [32]. However in the present study, no meaningful differences were found between 5 'nucleotidase enzyme activities of benign and malign tissues. Furthermore results of the present study show that aqueous extract of olive leaf inhibits 5 '-nucleotidase in benign gastric tissue ( $p=0.001)$ significantly. Although 5'-nucleotidase activities in malign tissues treated with olive leaf extract were found to be lower than those in the untreated tissues, the differences were not howevr significant from statistical points of wiew.

Xanthine oxidase is the last enzyme in purine degradation which converts purines to uric acid and hydrogen peroxide. Hydrogen peroxide is one of the reactive oxygen species. Although hydrogen peroxide can play a part in oxidative damage of DNA, and promotes malignant transformation, some studies have shown that this substance is able to kill cancer cells at higher concentrations [33].It has been reported that olive leaf extract inhibits xanthine oxidase activity in vitro [34] . However in our study, we found no significant differences between tissue xanthine oxidase activity values.

Our results show that olive leaf extract inhibits adenosine deaminase activity in malign gastric tissue significantly, but does not affect xanthine oxidase activity. It seems quite reasonable that accumulation of adenosine can exert anti-carcinogenic properties by inducing apoptosis and by anti-inflammatory effects. Additionally, inhibition of ADA and 5'nucleotidase can deplete nucleotide pool which is very important for new DNA synthesis. This study reveals preliminary information about different effects of olive leaf on purine metabolizing enzymes of benign and malign gastric tissues. Therefore, further in vivo studies should be conducted to clarify possible anti-carcinogenic effects of olive leaf.

\section{References}

1. Ferlay J (2015) Cancer incidence and mortality worldwide: sources, methods and major patterns in GLOBOCAN 2012. Int J Cancer 136(5): E359-E386.

2. Jemal A (2010) Global patterns of cancer incidence and mortality rates and trends. Cancer Epidemiol Biomarkers Prev 19(8): 1893-907.

3. Tavakoli (2012) Evaluation of effectiveness of herbal medication in cancer care: a review study. Iran J Cancer Prev 5(3): 144-156.

4. Karimi P (2014) Gastric cancer: descriptive epidemiology, risk factors, screening, and prevention. Cancer Epidemiol Biomarkers Prev 23(5): 700-713.

5. El SN, Karakaya S (2009) Olive tree (Olea europaea) leaves: potential beneficial effects on human health. Nutr Rev 67(11): 632-638.

6. Pereira AP (2007) Phenolic compounds and antimicrobial activity of olive (Olea europaea L. Cv. Cobrancosa) leaves. Molecules 12(5): 11531162

7. Cristalli G (2001) Adenosine deaminase: functional implications and different classes of inhibitors. Med Res Rev 21(2): 105-128.

8. Hunsucker SA, Mitchell BS, Spychala J (2005) The 5'-nucleotidases as regulators of nucleotide and drug metabolism. Pharmacol Ther 107(1): $1-30$.

9. Kostić DA (2015) Xanthine Oxidase: Isolation, Assays of Activity, and Inhibition. Journal of Chemistry 2015: 8.

10. Kelley EE (2010) Hydrogen peroxide is the major oxidant product of xanthine oxidase. Free Radical Biology and Medicine 48(4): 493-498.

11. Kumar R (2011) Xanthine oxidase inhibitors: a patent survey. Expert Opin Ther Pat 21(7): 1071-108. 


\section{Cancer Therapy \& Oncology International Journal}

12. Lowry OH, Farr AL, Randall RJ (1951) Protein measurement with the Folin phenol reagent. The Journal of biological chemistry 193(1): 265275.

13. Aebi H (1974) Catalase. Methods of enzymatic analysis. Bergmeyer HU(Eds.),. Verlag Chemie/Academic Press, London, UK, pp. 673-677.

14. Hashimato S (1974) A new spectrophotometric assay method of xanthine oxidase in crude tissue homogenate. Analitic Biochem 62(2): 425-435.

15. Donald W (1986) Enzymes. Tietz NW (Eds.), Text Book of Clinical Chemistry, Philadelphia, WB Saunders Company pp. 718-720.

16. Wahle KW (2010) Plant phenolics in the prevention and treatment of cancer. Adv Exp Med Biol 698: 36-51.

17. Talhaoui N (2015) Phenolic compounds in olive leaves: Analytica determination, biotic and abiotic influence, and health benefits. Food Research International 77(2): 92-108.

18. Bouallagui Z (2011) Hydroxytyrosol rich extract from olive leaves modulates cell cycle progression in MCF-7 human breast cancer cells. Food Chem Toxicol 49(1): 179-184

19. Bulotta S (2011) Antiproliferative and antioxidant effects on breast cancer cells of oleuropein and its semisynthetic peracetylated derivatives. Food Chem 127(4): 1609-1614.

20. Anter J (2011) A pilot study on the DNA-protective, cytotoxic, and apoptosis-inducing properties of olive-leaf extracts. Mutation Research/Genetic Toxicology and Environmental Mutagenesis 723(2) 165-170.

21. Mijatovic SA (2011) Multiple antimelanoma potential of dry olive leaf extract. Int J Cancer 128(8): 1955-1965.

22. Dekanski D (2009) Attenuation of cold restraint stress-induced gastric lesions by an olive leaf extract. Gen Physiol Biophys 28: 135-142.

23. Alirezaei M (2014) Antioxidant effects of oleuropein versus oxidative stress induced by ethanol in the rat intestine. Comparative Clinical Pathology 23(5): 1359-1365
24. Brown JB (2008) Therapeutic benefit of pentostatin in severe IL-10-/colitis. Inflamm Bowel Dis 14(7): 880-887.

25. de la Haba G, Bozzi A, Merta A, Unson C, Cantoni GL (1986) $S$-adenosylhomocysteinase: mechanism of reversible and irreversible inactivation by ATP, cAMP, and 2'-deoxyadenosine. Biochemistry 25(25): 8337-8342.

26.Chiang PK (2007) Biological Effects of Inhibitors of S-Adenosylhomocysteine Hydrolase. Pharmacol Ther 77(2): 115-134.

27. Antonioli L (2007) Inhibition of adenosine deaminase attenuates inflammation in experimental colitis. J Pharmacol Exp Ther 322(2): 435-442.

28. Saitoh M (2004) Adenosine induces apoptosis in the human gastric cancer cells via an intrinsic pathway relevant to activation of AMPactivated protein kinase. Biochemical Pharmacology 67(10): 20052011.

29. Fox JG, Wang TC (2007) Inflammation, atrophy, and gastric cancer. J Clin Invest 117(1): 60-69.

30. Hasko G (2008) Adenosine receptors: therapeutic aspects for inflammatory and immune diseases. Nat Rev Drug Discov 7(9): 759770 .

31. Gao ZW, Dong K, Zhang HZ (2014) The roles of CD73 in cancer. Biomed Res Int 2014(460654): 1-9.

32. Lu XX (2013) Expression and clinical significance of CD73 and hypoxiainducible factor-1alpha in gastric carcinoma. World J Gastroenterol 19(12): 1912-1918.

33. Lopez-Lazaro M (2007) Dual role of hydrogen peroxide in cancer: possible relevance to cancer chemoprevention and therapy. Cancer Lett 252(1): 1-8.

34. Flemmig J (2011) Olea europaea leaf (Ph.Eur.) extract as well as several of its isolated phenolics inhibit the gout-related enzyme xanthine oxidase. Phytomedicine 18(7): 561-566.

\section{Your next submission with Juniper Publishers will reach you the below assets}

- Quality Editorial service

- Swift Peer Review

- Reprints availability

- E-prints Service

- Manuscript Podcast for convenient understanding

- Global attainment for your research

- Manuscript accessibility in different formats

( Pdf, E-pub, Full Text, Audio)

- Unceasing customer service

Track the below URL for one-step submission https://juniperpublishers.com/online-submission.php 